\title{
An Adaptation Of The Balanced Scorecard For E-Government Service Delivery: A Content Analysis
}

Assion Lawson-Body, University of North Dakota, USA Laurence Mukankusi, University of North Dakota, USA Glenn Miller, University of North Dakota, USA

\begin{abstract}
E-government services refer to the emerging area of IS and IT services that are delivered electronically. The way that government agencies design and deliver services and configure and deploy underlying information and communications technologies, is central to the performance of e-government service delivery. This paper examines the effectiveness of website-supported Balanced Scorecard's four dimensions (innovation and learning, internal process, veteran value proposition, and financial) in improving e-government service delivery performance. The study used content analysis to analyze the data obtained from a sample of 19 county veteran service officers (CVSOs) to test the hypotheses. CVSOs use websites to serve veterans on a Governmentto-Citizen (G2C) basis. The results show that the different aspects of the relations between CVSOs and veterans fit with the four interrelated balanced scorecard factors. The results also show that three of the four website-supported Balanced Scorecard dimensions (learning and innovation, internal process, and veteran value proposition) have a positive impact on e-government service delivery performance. However, the impact of the fourth website-supported Balanced Scorecard perspective (financial) on e-government service delivery performance is different because of the digital divide among the various generations of veterans.
\end{abstract}

Keywords: Veterans, Balanced Scorecard, Websites, E-government

\section{INTRODUCTION}

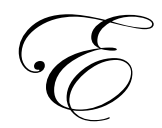

-government may influence the way government services are delivered to citizens. E-government creates new forms of government service delivery system, such as the electronic matching of government agencies and citizens. The information systems (IS) community has given significant attention to government-citizen relationships supported by Information technology (IT) such as Internet's web portals. Several authors have argued that these concepts can play a key role in e-government service delivery performance measurements. Financial accounting measurements are extensively used to evaluate government performance (Wright et al., 1999; Hsu, 2005), but they do not reveal adequately the benefits of investing in IT. Financial accounting measurements do inform managers of historical outcomes, but they do not indicate why those results were achieved or what managerial actions have to be performed to improve future results (Wright et al., 1999). Because the excessive reliance on financial accounting performance measurements is inadequate and can be misleading, Wright et al. (1999) suggested a Balanced Scorecard theory as a consistent performance measurement tool for the use of IT.

In government, IT and information are public property, not a proprietary resource to be protected and exploited for competitive advantage (Dufner et al., 2002); therefore, performance measurement is important to assess e-government efforts. A government needs to track what is working and what is not and assure citizens that the government's time and funds are being well spent (Stowers, 2004). Some traditional performance measures may be appropriate for e-government, but e-government service is different in its delivery modes and expectations. E- 
government service delivery applications are relatively new and government service providers and researchers can only learn so much from traditional cost-benefit analyses. Therefore, new performance measures need to be developed to provide accountability for jurisdictions' e-government efforts. In addition, the significance of aligning the usability of websites with government service delivery strategies is widely recognized (Griffith et. al., 2003), but the lack of appropriate methodologies prevents government units and their constituents from integrating website projects with e-government service delivery performance.

This paper addresses the issue of delivering electronic services using the concept of an accepted management tool--the Balanced Scorecard. In other words, the website-supported Balanced Scorecard dimensions may be used to improve e-government service delivery performance. Like many other innovative technologies, government websites can generate sustainable electronic service delivery performance if the technology is used for improving the operational efficiency of government services.

This research deals with G2C e-government, focusing on government websites that county veterans service officers (CVSOs) use to deliver electronic services to veterans. Veterans are the nation's population who have been discharged or retired after serving active duty with the United States Armed Forces. CVSOs are county employees. Veterans interact with CVSOs when requesting government benefits or having questions about them.

This paper is organized as follows. Section II contains the description of the Balanced Scorecard theory. In Section III, government service delivery performance is examined. In Section IV, the research model and hypotheses are presented. In Section V, the methodology is outlined. In Section VI, the results and findings are examined. In Section VII, the conclusion and discussion of this paper are presented.

\section{BALANCED SCORECARD THEORY}

The early experiences of companies using Balanced Scorecard have demonstrated that it meets several managerial needs (Kaplan and Norton, 1992). When a company includes both financial and non-financial indicators together in a sheet, it is called a Balanced Scorecard (Pandey, 2005). By using the Balanced Scorecard, companies must create a system that simultaneously aligns and integrates four interrelated perspectives: 1) customer focus, 2) internal process focus, 3) learning and innovation focus, and 4) financial focus (Kaplan and Norton, 1992; Hsu, 2005). Balanced Scorecard is not only a tool for performance assessment, but also a key driver to a business organization's success (Hsu, 2005).

Prior to this study, many authors such as Wright et al. (1999) and Huang and Hu (2004) have examined the integration of IT or web services with Balanced Scorecard. Building and expanding on previous efforts (Huang and $\mathrm{Hu}, 2004)$, we address the issue of e-government services delivery performance using the Balanced Scorecard approach.

\section{E-GOVERNMENT SERVICE DELIVERY PERFORMANCE}

Governments use IT to deliver valuable services to their citizens at a lower cost. E-government services refer to the emerging area of IS and IT services that are delivered electronically (Ramesh and Tiwana, 2001). The way that government agencies design and deliver services and configure and deploy underlying information and communications technologies is central to the performance of e-government service delivery.

\section{THE RESEARCH MODEL AND HYPOTHESES}

In the research model shown in Figure 1, the dependent variable will be drawn from e-government service delivery performance. The independent variables will be drawn from the website-supported four interrelated Balanced Scorecard business perspectives. Because these four interrelated business perspectives are supported by websites used by CVSOs on a G2C basis in order to serve veterans, they have been adapted as follows: websitesupported innovation and learning perspective (this perspective is based upon performance indicators of how the CVSOs innovate and learn through government websites); website-supported internal process perspective (this 
perspective demonstrates how CVSOs use websites to identify performance indicators via their internal capabilities); website-supported veteran value proposition perspective (this perspective shows how CVSOs use websites to identify outcome measures of their works in order to create value for current and future veterans); and websitesupported financial perspective (this perspective indicates how CVSOs use websites to take into account outcome measures of their past performance.)

Figure 1

Research Model (Adapted from the Balanced Scorecard Framework of Huang and Hu, 2004)

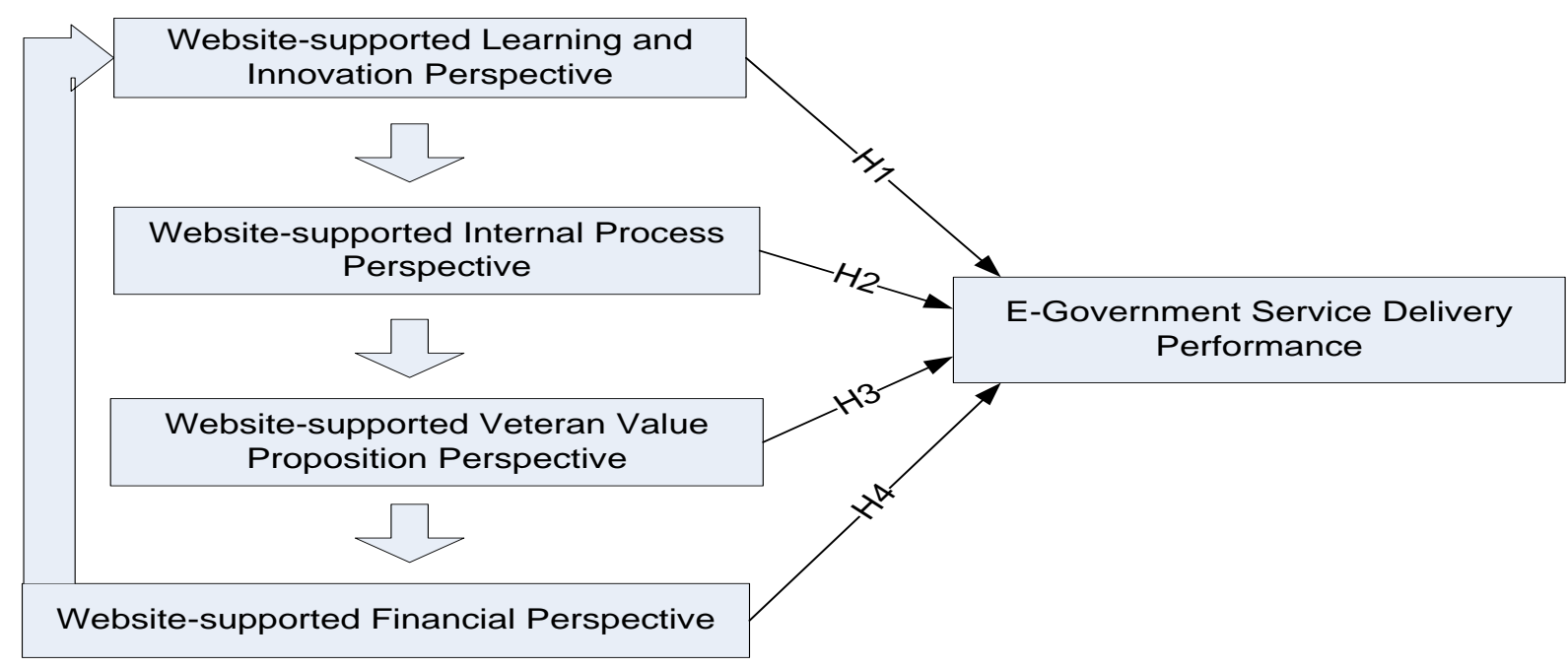

This research model enables us to test the following hypotheses:

Hypothesis 1: The website-supported learning and innovation perspective will have a positive effect on egovernment service delivery performance.

Hypothesis 2: The website-supported internal process perspective will have a positive effect on e-government service delivery performance.

Hypothesis 3: The website-supported veteran value proposition perspective will have a positive effect on egovernment service delivery performance.

Hypothesis 4: The website-supported financial perspective will have a positive effect on e-government service delivery performance.

\section{METHODOLOGY: MULTIPLE CASE STUDIES}

This research focuses on government websites that deliver electronic services to veterans. The website of the North Dakota Government Rural Outreach (GRO) Initiative has been selected as the sample U.S. government website for this research. That website has been chosen because it has a component dedicated to veterans and CVSOs.

The procedure used to process data was based on the guidelines suggested by Churchill (1979). In order to follow these guidelines, multiple case studies have been conducted. In total, 19 CVSOs of 17 counties in North Dakota were asked to participate in the multiple case studies. The interviews were held individually with each 
CVSO for one hour. The interviews were tape-recorded, and the texts of the interviews were transcribed and entered into Windows Word software. To help conduct the interviews, an interview guide was used.

The study used content analysis to analyze the data obtained from a sample of CVSOs to test the hypotheses. The common response is obtained by using the generalized answer from all CVSOs. The procedure for data analysis was based on totaling the overall counts of messages coded in each category and the analysis of the messages. Each research variable has played the role of category. Occurrences of the messages in each category have been analyzed to determine relative importance. Higher relative counts reflect the significance of the particular message within the specific category.

\section{RESULTS AND FINDINGS}

\section{Procedures For Testing The Hypotheses}

In this research, Chi-square, a non-parametric test of statistical significance for bivariate tabular analysis, was used to test the hypotheses and analyze data. The test of the hypotheses determined whether or not two different samples (of people or texts) are significantly different in some aspect of their behaviors. Then it can be generalized from the samples that the populations are also different in the behaviors (Connor-Linton, 2003).

Chi-square was selected in this research because it is a rough estimate of confidence; it accepts weaker, less accurate data as input than do parametric tests (like t-test, f-fisher, and analysis of variance) (Connor-Linton, 2003). Also, it does not require the sample data to be more or less normally distributed in the population from which the sample is drawn (Connor-Linton, 2003). But Chi-square requires that data are in the form of raw frequency counts of phenomena in two or more mutually exclusive and exhaustive categories (Connor-Linton, 2003).

\section{Hypothesis Testing (H1)}

Table 1 summarizes the number, percent, and chi-square of messages related to the impact of the websitesupported learning and innovation perspective on e-government service delivery performance.

Table 1

Number, Percent, and Chi-square of learning and innovation

\begin{tabular}{|c|c|c|c|c|}
\hline Coded Messages & Number & Percentage (\%) & Number of CVSOs & Chi-Square \\
\hline IVSS & 41 & 77 & 14 & \multirow[t]{3}{*}{$15.86 * * *$} \\
\hline IVNS & 12 & 23 & 5 & \\
\hline Total & 53 & 100 & 19 & \\
\hline YVCB & 37 & 71 & 11 & \multirow{3}{*}{$9.30 * * *$} \\
\hline YVNC & 15 & 29 & 7 & \\
\hline Total & 52 & 100 & 18 & \\
\hline & & & & \\
\hline TVSI & 29 & 81 & 14 & \multirow[t]{3}{*}{$13.44 * * *$} \\
\hline TVNI & 7 & 19 & 3 & \\
\hline Total & 36 & 100 & 17 & \\
\hline HTST & 41 & 87 & 16 & \multirow{3}{*}{$43.08 * * *$} \\
\hline HTNT & 6 & 13 & 3 & \\
\hline Total & 47 & 100 & 19 & \\
\hline TFEE & 20 & 44 & 7 & \multirow{3}{*}{0.55} \\
\hline TFNE & 25 & 56 & 12 & \\
\hline Total & 45 & 100 & 19 & \\
\hline \multicolumn{4}{|c|}{ The total chi-square value for Table 1 is } & $82.23 * * *$ \\
\hline
\end{tabular}

$* * * \mathrm{P}<0.001$ 
Table 1 presents the results of chi-square tests carried out to determine whether positive messages about the website-supported learning and innovation perspective predominate over negative messages about the websitesupported learning and innovation perspective. The results show that positive messages were significantly greater than negative messages $(82.23$ at $\mathrm{p}<0.001)$. Thus, Hypothesis 1 , which states that website-supported learning and innovation perspective will have a positive effect on e-government service delivery performance, is supported.

\section{Hypothesis Testing (H2)}

Table 2 summarizes the number, percent, and chi-square of messages related to the impact of the websitesupported internal process perspective on e-government service delivery performance.

Table 2

Number, Percent, and Chi-square of internal process

\begin{tabular}{|c|c|c|c|c|}
\hline Coded Messages & Number & Percentage (\%) & Number of CVSOs & Chi-Square \\
\hline IFOF & 25 & 45 & 10 & \multirow[t]{3}{*}{0.64} \\
\hline IFNF & 31 & 55 & 9 & \\
\hline Total & 56 & 100 & 19 & \\
\hline IAFV & 32 & 84 & 17 & \multirow{3}{*}{$17.78 * * *$} \\
\hline IANV & 6 & 16 & 2 & \\
\hline Total & 38 & 100 & 19 & \\
\hline & & & & \\
\hline VCWR & 29 & 78 & 15 & \multirow[t]{3}{*}{$11.91 * * *$} \\
\hline VCNR & 8 & 22 & 4 & \\
\hline Total & 37 & 100 & 19 & \\
\hline VCUI & 31 & 54 & 11 & \multirow{3}{*}{0.43} \\
\hline VCNI & 26 & 46 & 8 & \\
\hline Total & 57 & 100 & 19 & \\
\hline \multicolumn{4}{|c|}{ The total chi-square value for Table 2 is } & $30.76^{* * *}$ \\
\hline
\end{tabular}

$* * * \mathrm{p}<0.001$

Table 2 presents the results of chi-square tests carried out to determine whether positive messages about the website-supported internal process perspective predominate over negative messages about the website-supported internal process perspective. The results show that positive messages were significantly greater than negative messages (30.76 at $\mathrm{p}<0.001)$. Thus, Hypothesis 2, which states that website-supported internal process perspective will have a positive effect on e-government service delivery performance, is supported.

\section{Hypothesis Testing (H3)}

Table 3 summarizes the number, percent, and chi-square of messages related to the impact of the websitesupported veteran value proposition perspective on e-government service delivery performance.

Table 3 presents the results of chi-square tests carried out to determine whether positive messages about the website-supported veteran value proposition perspective predominate over negative messages about the websitesupported veteran value proposition perspective. The results show that positive messages were significantly greater than negative messages $(37.83$ at $\mathrm{p}<0.001)$. Thus, Hypothesis 3 , which states website-supported veteran value proposition perspective will have a positive effect on e-government service delivery performance, is supported. 
Table 3

Number, Percent, and Chi-square of veteran value proposition

\begin{tabular}{|c|c|c|c|c|}
\hline Coded Messages & Number & Percentage $(\%)$ & Number of CVSOs & Chi-Square \\
\hline DWVO & 29 & 59 & 10 & \multirow[t]{3}{*}{1.65} \\
\hline DWNO & 20 & 41 & 9 & \\
\hline Total & 49 & 100 & 19 & \\
\hline IPVV & 42 & 71 & 11 & \multirow{3}{*}{$10.59 * * *$} \\
\hline IPNV & 17 & 29 & 8 & \\
\hline Total & 59 & 100 & 19 & \\
\hline IFIV & 33 & 77 & 14 & \multirow{3}{*}{$12.30 * * *$} \\
\hline IFNV & 10 & 23 & 4 & \\
\hline Total & 43 & 100 & 18 & \\
\hline IICV & 36 & 77 & 12 & \multirow{3}{*}{$13.29 * * *$} \\
\hline IINV & 11 & 23 & 5 & \\
\hline Total & 47 & 100 & 17 & \\
\hline \multicolumn{4}{|c|}{ The total chi square value for Table 3 is } & $37.83 * * *$ \\
\hline
\end{tabular}

$* * * \mathrm{p}<0.001$

\section{Hypothesis Testing (H4)}

Table 4 summarizes the number, percent and chi-square of messages related to the impact of the websitesupported financial perspective on e-government service delivery performance.

Table 4

Number, Percent, and Chi-square of financial perspective

\begin{tabular}{|c|c|c|c|c|}
\hline Coded Messages & Number & Percentage (\%) & Number of CVSOs & Chi-Square \\
\hline & & & & \multirow[t]{4}{*}{$5.91 * *$} \\
\hline DCAB & 21 & 34 & 8 & \\
\hline DCNB & 40 & 66 & 9 & \\
\hline Total & 61 & 100 & 17 & \\
\hline & & & & \multirow{4}{*}{$5.58 * *$} \\
\hline ATCD & 38 & 65.50 & 10 & \\
\hline ATND & 20 & 34.50 & 9 & \\
\hline Total & 58 & 100 & 19 & \\
\hline
\end{tabular}

$* * \mathrm{P}<0.025$

Table 4 presents the results of chi-square tests carried out to determine whether there are any significant differences between:

- the proportion of increase of initial cost and decrease of initial cost messages, and

- $\quad$ the proportion of increase of cost over time and decrease of cost over time messages.

The results show that decrease of cost over time messages were significantly greater than increase of cost over time messages. Thus, Hypothesis 4, which states that the website supported financial perspective will have a positive effect on e-government service delivery performance, is supported $(5.58$ at $\mathrm{p}<0.025)$. This finding suggests that, as time goes by, a different group or generation of veterans might be comfortable with using the Internet. However, increase of initial cost messages were significantly greater than decrease of initial cost messages (5.91 at 
$\mathrm{p}<0.025)$. The result also shows that the website-supported financial perspective has negative impact on egovernment service delivery performance at the earliest stage of the website's use to deliver service to veterans because of the digital divide among various generations of veterans.

\section{DISCUSSION AND CONCLUSION}

The results show that the different aspects of the relations between CVSOs and veterans fit with the four interrelated Balanced Scorecard factors. The results also show that three of the four website-supported Balanced Scorecard dimensions (learning and innovation, internal process and veteran value proposition) have a positive impact on e-government service delivery performance. However, the impact of the fourth website-supported Balanced Scorecard perspective (financial) on e-government service delivery performance is different because of the digital divide among the various generations of veterans.

As time goes by, that finding could change because the high cost associated with the earliest stage of the website's use by CVSOs to serve veterans will decrease. This decrease will result from a different group of veterans who might be comfortable using the Internet. Therefore, the digital divide gap between veterans will be small in terms of using the Internet and make them more self-sufficient as far as using technology. Finally, the results also show that to increase e-government service delivery performance, veteran self-service needs to be promoted on websites. Then, e-government service delivery will free up CVSOs and allow them to focus less on routine tasks that could be easily handled by websites.

Digital divide is frequently referred to as the gap between technology "haves" and "have nots" (Sipior et al., 2004). Community members like CVSOs can run programs with assistance from volunteers to reduce the digital divide gap. The programs will allow veterans to learn computer skills and their discomfort will decline (Sipior et al., 2003).

The findings of this study also demonstrate the importance of usability of a website. The International Organization for Standardization defines usability as the extent to which a service can be used by specified users to achieve specified goals with effectiveness, efficiency, and satisfaction in a specified context of use (Cetiner and Ryan, 2004). Therefore, veterans can benefit from the usability functionalities of websites to receive e-government service to achieve goals with satisfaction.

Future research is necessary because this research model must be tested further. E-government technology has attracted significant attention among researchers and development communities. Many exciting research issues are being addressed and some are yet to be addressed, and we hope that this paper inspires others to do future research by expanding or enhancing this research model.

\section{AUTHOR INFORMATION}

Dr. Assion Lawson-Body is an Associate Professor of Information Systems, College of Business and Public Administration, University of North Dakota. He obtained his Ph.D. and MBA in MIS from Laval University, Quebec, Canada. He also received DESS-CTCI from IAE, University of Montpellier 2, France. His publications have appeared in numerous Journals, Reviews, Books and Conference Proceedings in the field of Information Systems. His international reputation allows him to teach as a visiting professor at IFGCar, Port-Au-Prince, Haiti and at ESIDEC, Metz, France. He has consulted for Small Business Development Center (SBDC) and Government Rural Outreach Initiative (e-government) in North Dakota.

Mrs. Laurence Mukankusi is an Instructor of Accountancy, Department of Accountancy, College of Business and Public Administration, University of North Dakota. She obtained her MBA from University of North Dakota. She also received her BBA in Accountancy from Laval University, Quebec, Canada. Her publications have appeared or will appear in Journal of Electronic Commerce in Organizations and other outlets. She is also working in several conference proceedings. Her current teaching and research focuses on Accounting Principles, E-Health, Revenue Recognition, E-commerce, E-Business, and E-government. 
Glenn Miller became the University of North Dakota (UND)'s Director for the Government Rural Outreach (GRO)

Initiative on June 1, 2002. His publications have appeared or will appear in E-Business Review and Encyclopedia of E-commerce, E-government and M-commerce. He has also published in several conference proceedings such as IRMA, International Academy of E-Business, etc. Prior to joining UND, Glenn was an independent sales and marketing consultant. He spent 33 years at Control Data.

\section{REFERENCES}

1. Cetiner, M., \& Ryan, T. (2004) How to improve the usability of government web sites. Proceedings of the Seventh Conference of the Southern Association for Information Systems. 1(1), 65-68.

2. Churchill, G. A. (1979) A Paradigm for developing better measures of marketing constructs. Journal of Marketing Research, 16(1), 64-73.

3. Connor-Linton, J. (2003) Chi-Square Tutorial. Retrieved June $20^{\text {th }}, 2005$ from http://www.georgetown.edu/faculty/ballc/webtools/web_chi tut.html

4. Dufner, D., Holley, L., \& Reed, B. (2002) Can private sector strategic information systems planning techniques work for the public sector? Communications of the Association for Information Systems, 8(27), 413-431.

5. Griffith, T., Sawyer, J., \& Neale, M. (2003) Virtualness and Knowledge in Teams: Managing The Love Triangle of Organizations, Individuals, and Information Technology. MIS Quarterly, 2(27), 265-287.

6. Hsu, K-H., (2005) Using Balanced Scorecard and Fuzzy Data Envelopment Analysis for Multinational R \& D Project Performance Assessment, The Journal of American Academy of Business, Cambridge, 1(27), 189-196.

7. Huang, D. C, \& Hu, Q. (2004) Integrating web services with competitive strategies : The balanced Scorecard approach. Communications of the Association for Information Systems, 1(13), 57-80.

8. Kaplan, R., \& Norton, D. P. (1992) The Balanced Scorecard - Measures That Drive Performance. Harvard Business Review, P. 71-79.

9. Pandey, I.M. (2005) Balanced Scorecard: Myth and Reality. The Journal for Decision Makers, 1(30), 5166.

10. Ramesh, B. \& Tiwana A. (2001) e-Services: Models and Methods for Design, Implementation, and Delivery. Proceedings of the $34^{\text {th }}$ Hawaii International Conference on System Sciences, 1 page.

11. Sipior, J. C., Ward, B. T., Volonino, L. \& Marzec, J. Z. (2004) A Community Initiative That Diminished The Digital Divide, Communications of the Association for Information Systems, 13(1), 29-56.

12. Stowers, G. N. L. (2004) Measuring the Performance of E-Government. E-Government Series, 1-52.

13. Wright, W., Smith, R., Jesser, R., \& Stupeck, M. (1999) Information Technology, Process Reengineering and Performance Measurement: A Balanced Scorecard Analysis of Compaq Computer Corporation. Communications of the Association for Information Systems, 8(1), 1-47. 